\title{
Why isn't guardianship more popular in Scotland?
}

\author{
AnNe E. Weatherhead, Medical Officer, Mental Welfare Commission for Scotland, \\ 25 Drumsheugh Gardens, Edinburgh EH3 7RB
}

Guardianship can offer a measure of control and support in the community to individuals suffering from any type of mental disorder, be it mental illness or mental handicap, yet there were only 14 new guardianship cases in Scotland in 1989, compared with 3,604 episodes of detention under the Mental Health (Scotland) Act 1984 (MWC Annual Report 1989), and out of an estimated total of mentally disordered people in Scotland of more than half a million (Titterton, personal communication).

Where mental illness is the type of mental disorder involved, it can be in any of its many forms, including dementia.

Where mental handicap is the type of mental disorder involved, in Scotland it does not have to amount to mental impairment (mental handicap combined with abnormally aggressive or seriously irresponsible conduct), so guardianship could be available to many individuals who would not meet the criteria for compulsory detention in hospital.

\section{So why is guardianship being used so seldom?}

There are a number of possible reasons:

\section{Doubt about criteria for guardianship}

The Mental Health (Scotland) Act 1984 states that (Section 36):

A person may be received into guardianship on the grounds that:

(a) he is suffering from mental disorder of a nature or degree which warrants his reception into guardianship, and

(b) it is necessary in the interests of the welfare of that patient that he should be so received.

Definitions like this are less than helpful to professionals who are considering the use of guardianship for the first time, and uncertainty over criteria could lead to rejection of the whole idea from the outset, particularly as the Code of Practice in Scotland offers no help, excluding, as it does, consideration of guardianship. The Notes on the Act do provide some guidance, however, and as experience increases, so should confidence in selecting suitable cases.

\section{Limited powers given to guardians}

Under the 1960 Mental Health (Scotland) Act, guardians were given wide general powers. These were narrowed down in the 1984 Act, so that now only three specific powers are given to guardians:

(a) power to require the patient to reside at a particular place

(b) power to require the patient to attend at specific places and times for medical treatment, occupation, education or training

(c) power to require access to the patient to be given to specific persons (for example, a doctor, MHO, etc).

These specific powers given to guardians may bear no direct relationship to areas of vulnerability actually demonstrated by particular mentally disordered individuals - they may, for instance, be sexually or financially vulnerable - so not surprisingly doubt can arise about the suitability of a guardianship order in these cases.

It does not appear, however, that applications are being turned down by the courts simply because the opinions given about the medical or welfare grounds are not directly linked to the specific powers given to guardians - so this should not act as a disincentive.

\section{Not a Community Treatment Order}

Although mental illness provides a perfectly legitimate medical ground for guardianship, the fact that the power to enforce the giving of medication is not a statutory part of the arrangement means that guardianship is seldom used for chronically psychotic patients - who might be thought to be the very people, in other ways, most likely to benefit, and whose welfare MHOs and others might well wish to see improved by its use.

It could be used to ensure attendance at an outpatient clinic even without the enforced giving of medication (this would at least allow review of the person's condition and facilitate compulsory admission if such were indicated) but a measure of co-operation would be required from the individual and his professional and/or family carers for such a strategy to be effective (see also below). 


\section{Might prove unworkable}

When guardianship is set up, wise professionals will consider what should be done if the person on guardianship fails to meet the requirements of the guardian. This may prove difficult. If guardianship is being used, for instance, to require someone to reside at a particular place and the individual repeatedly finds ways of circumventing the arrangement, there may be no effective sanction if the person does not meet the criteria for compulsory admission to hospital. There is an obvious practical limit to the number of times Section 44 of the 1984 Act can be invoked to compel return to a particular place of residence.

Again, if guardianship is being used to require a patient to attend at a specific place for occupation or training, etc, and that person continually declines to co-operate, the arrangement may very soon break down. Professional staff cannot always be on hand to actively encourage attendance, and even if this were possible, there is the added problem for staff of knowing just how far they can go in insisting. Repeated confrontations are demoralising for all concerned, and the Act does not specifically give powers to remove and convey a resistive individual.

\section{Change in place of residence}

If an individual is likely to move from Scotland to England, either impulsively, or as part of a plan, then guardianship authorised in Scotland will lose its effectiveness as soon as that person crosses the Border. This could prove a disincentive to its use in some cases, as delays would occur in seeking a second order under English legislation, with the added problem that the medical grounds for guardianship are not the same in the two countries.

\section{The faceless guardian}

Guardians are not always named individuals - more often than not guardianship is vested in the local authority, and this is difficult for some patients to understand. "How can my guardian be a group of people?".

The impersonal nature of guardianship by the local authority can be overcome by having a named individual social worker within the authority carrying out the functions of guardian, but this can be confusing for the patient when a different social worker may be carrying out the statutory visits to the patient, which are specified in regulations, and are required in every case of guardianship.

To some, it appears undesirable that local authorities have this dual function, although this is not likely to be a strong reason for the rejection of guardianship in specific cases. Where there is an identified need for a close relationship with a particular carer with statutory powers, a non-related individual may be appointed instead, if authorised by the local authority. This can happen, for instance, when a young person in foster care reaches the age of 18 .

\section{Problems with finances}

The Act specifically prevents guardians from intromitting with the funds of those in their charge.

This does not often lead to practical problems, in that local authorities devise arrangements whereby different departments are involved, and where more than one signature is required to carry out any financial transactions on behalf of a patient.

Where financial matters are an important component of case management, however, guardianship alone is unlikely to be the preferred option. Consideration may have to be given to the appointment of a curator bonis, for instance.

\section{How do you judge quality of life?}

Elderly patients with dementia are a group of people who suffer from mental disorder and whose welfare is often at risk.

The power of specifying the place of residence makes guardianship appear a suitable method of effecting admission to residential care.

Most patients soon accept the care that is provided and forget the place they came from. Others do not, and constantly want to return. They are likely to have been those who, before their memory began to fail, would have made it very plain to all they knew that they wished to die in their own homes, however poor their eventual ability to care for themselves.

If the unhappy patient does not present problems to others by being, for example, a fire risk or by leaving gas or water taps on, are deteriorating standards of self-care in themselves sufficient to warrant compulsory removal from the home of a life-time?

Questions like this may make some hesitate to use guardianship where at first sight it can appear suitable. Compulsory residence in a community setting can be seen by the sufferer as being just as restrictive as detention in hospital.

\section{Insufficient review by the Sheriff in some circumstances?}

Normally reception into guardianship is approved by a Sheriff after consideration of an application from a Mental Health Officer (who will give an opinion as to whether the welfare grounds are met), supported by two medical recommendations (which should state the type of mental disorder, and include an opinion as to whether the medical grounds are met).

A patient who is liable to be detained in hospital can, however, be transferred from detention to 
guardianship by the managers of that hospital with the consent of a local authority, but without any further involvement of the Sheriff. Some might feel the Sheriff should be involved again at this stage, as the onset of detention may have taken place some considerable time earlier, but this is not likely to be a major disincentive to its use, as the needs of the individual should have been well examined in hospital before transfer to guardianship. The right of appeal against guardianship, either to the Sheriff or to the Mental Welfare Commission, allowing full review of the case, should not be forgotten.

\section{A question of resources?}

If an offence has been committed, Sheriffs may, with the agreement of the local authority, order guardianship in an attempt to introduce some stability in the lives of appropriate individuals - those, for instance, who have personality disorders, who are of limited intelligence, who do not remain at an address for any length of time and who constantly reoffend. Local authorities themselves may initiate consideration of guardianship when both the medical and welfare grounds for its use appear to be met, although no offence may have been committed.

Individuals in need can be very demanding in terms of time, energy and resources, however, and local authorities are unlikely to welcome widespread use of guardianship orders if resources are limited.

\section{Comment}

A number of reasons have been suggested for the infrequent use of guardianship in Scotland.

Despite its apparent unpopularity, it has to be said that there are those who have found it to be an effec- tive and appropriate means of providing a measure of statutory care and support to selected mentally disordered individuals in the community.

Since the inception of the 1984 Act there have been less than two hundred guardianship applications approved in Scotland. It is not known at present how many applications have failed.

The Mental Welfare Commission (1987) has made it clear that it would not wish to recommend greater or lesser use of this provision of the Mental Health (Scotland) Act 1984, but as long as legislation remains as it is, guardianship should not be overlooked as one possible strategy to be considered in the ongoing support of individual patients in the community.

\section{Acknowledgement}

The helpful comments of professional colleagues are acknowledged with gratitude, as is the information provided by $\mathbf{M}$. Titterton (research worker assisting the MWC in 1990).

\section{References}

Mental Health (Scotland) Act 1984. HMSO.

SHHD Notes on the Act. HMSO.

Mental Welfare Commission for Scotland Annual Reports 1987 and 1989. HMSO.

\section{Addendum}

The Mental Welfare Commission indicated in 1989 its intention to undertake a review of guardianship, including a survey of cases known to exist in Scotland in 1988. It is hoped that this will be published in 1991. 